A Systematic Review of the Application of Interactive Virtual Reality to Sport

David L. Neumann ${ }^{\mathrm{a}, \mathrm{b}}$, Robyn L. Moffitt ${ }^{\mathrm{a}, \mathrm{b}}$, Patrick R. Thomas ${ }^{\mathrm{b}}$, Kylie Loveday ${ }^{\mathrm{a}}$, David P. Watling ${ }^{\mathrm{a}}$, Chantal L. Lombard ${ }^{\mathrm{a}}$, Simona Antonova ${ }^{\mathrm{a}}$, \& Michael A. Tremeer ${ }^{\mathrm{a}}$

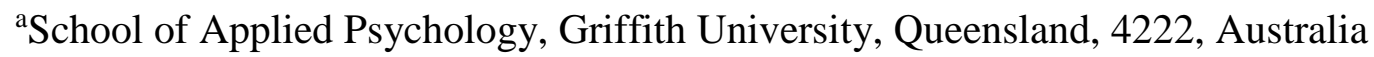
${ }^{\mathrm{b}}$ Menzies Health Institute Queensland, Australia

\footnotetext{
Author Notes

Please direct correspondence to Associate Professor David Neumann, School of Applied Psychology, Griffith University, Queensland 4222, Australia. Facsimile: +61 7 55337901. Email: d.neumann@griffith.edu.au.
} 


\begin{abstract}
Virtual reality (VR) technology is being increasingly used by athletes, coaches, and other sport-related professionals. The present systematic review aimed to document research on the application of VR to sport to better understand the outcomes that have emerged in this work. Research literature databases were searched and the results screened to identify articles reporting applications of interactive VR to sport with healthy human participants. Twenty articles were identified and coded to document the study aims, research designs, participant characteristics, sport types, VR technology, measures, and key findings. From the review, it was shown that interactive VR applications have enhanced a range of performance, physiological, and psychological outcomes. The specific effects have been influenced by factors related to the athlete and the VR system, which comprises athlete factors, VR environment factors, task factors, and the non-VR environment factors. Important variables include the presence of others in the virtual environment, competitiveness, task autonomy, immersion, attentional focus, and feedback. The majority of research has been conducted on endurance sports, such as running, cycling, and rowing, and more research is required to examine the use of interactive VR in skill-based sports. Additional directions for future research and reporting standards for researchers are suggested.
\end{abstract}

Keywords: virtual reality, sport, exercise, systematic review 


\section{A Systematic Review of the Application of Interactive Virtual Reality to Sport}

The application of computer-based technology to sport is an area of intense interest. Such technologies include computerised modelling, data acquisition and analysis, mobile computers, and information technology networks (Baca et al. 2009). Virtual reality (VR) is another technology and it was first applied to sport research in the 1990s, although there has been a resurgence of interest in recent years. VR refers to a computer-simulated environment that aims to induce a sense of being mentally or physically present in another place (Baños et al. 2000; Sherman and Craig 2002). An important feature of VR is that the individual can interact with the environment. In the context of sport, interaction might occur through an exertion interface (Mueller et al. 2007). For example, physical effort on a machine such as an ergometer can be related to the speed of movement through a virtual race course. Motion capture video systems, infrared beams, and wearable sensors are other approaches that can be used to translate physical actions into virtual sport performance.

The key elements that define VR applications to sport are the use of computer generated sport-relevant content and a means for the athlete to interact with the virtual environment. When defined in this way, the application of VR to sport has a number of strengths. As noted by Hoffman et al. (2014), the VR environment can be controlled and manipulated in specific and reproducible ways. Hoffman et al. used these characteristics to train participants to use a rowing race pacing strategy. VR can also be used for assessment, to gain feedback on performance, and to practice specific skills. The VR environment does not need to be limited to a single person. Other individuals may be present such as a coach, teammate, or competitor even if they are physically located in another place. The ability to connect with individuals via the Internet allows for interaction without the need for travel. Finally, the increasing availability of commercially produced software or full VR systems avoids the need for specialised technical expertise and allows VR to be used in local gyms and at home.

The present study aimed to provide a systematic review of research on VR applications 
to sport. The PsycINFO, SPORTDiscus, Scopus, Google Scholar, and Cochrane Library databases were first searched for the existence of similar reviews. The search yielded systematic reviews on VR in physical rehabilitation (e.g., Laver et al. 2015), VR in psychological interventions (e.g., Meyerbröker and Emmelkamp 2010), and the use of exergames or active videogames (e.g., Guy et al. 2011; Larsen et al. 2013; Peng et al. 2013). The search helped to minimise overlap with existing reviews. Accordingly, the present review focused on VR applications to sport and sport-related exercise with healthy individuals. Studies were included if they were based on recognised sports even if those sports are used as a component of physical conditioning or fitness programs (e.g., cycling, running, rowing). As a result, this review focused on sports-based tasks as distinct from research with interactive videogame systems that promote physical activity through gameplay (i.e., exergames).

The broad question examined in the present review was: What is known about the application of VR to sport? In particular, the review aimed to provide a definition of VR when used for sports. A further aim was to document the aims, methods, and the broad findings from the research conducted to date. Past research may be interpreted within the context of existing theories in sport and exercise, but of particular focus in the present review were those factors that are unique to VR applications to sport. The review also aimed to identify the gaps in the research to date and develop recommended reporting standards for researchers who apply VR to sport.

\section{Literature Review Method}

The literature search and selection method followed the Preferred Reporting Items for Systematic Review and Meta-Analyses (PRISMA) guidelines (Liberati et al. 2009) and the use of inclusion and exclusion rules described by Meline (2006). Initially, the SPORTDiscus and PsycINFO Databases were searched. The PsycINFO database includes sport and exercise psychology journals, in addition to the ACM Transactions on Applied Perception, the ACM Transactions on Computer-Human Interaction, and the IEEE Transactions on Professional 
Communication. The search was conducted using the terms: (sport* OR exercis* OR fitness OR physical train* or physical activit*) AND (virtual realit* OR virtual environment* OR virtual world* OR virtual system* OR virtual partner*). The search was limited to articles published from 1990 and up to the date of the search (February, 2016) and included articles that were in press. In addition, to identify any missed articles due to the inconsistent use of terms (e.g., virtual reality versus virtual competitor) the reference lists of the articles selected for final inclusion from the database search were examined. An examination was also made of the citations of these articles, as collated from the Scopus database.

The database search yielded 263 articles from the PsychINFO database and 377 articles from the SPORTDiscus database for a total of 640 articles. This reduced to 620 articles following removal of duplicates. A search of the reference lists and citations yielded a further 66 unique articles. Articles were screened for exclusion or inclusion by two individuals in a two-step process: title and abstract (Step 1) and the full article (Step 2) ${ }^{1}$. The following exclusion criteria were used: date (published before 1990), language (not published in English language), source (a dissertation, thesis, abstract only, magazine article, or not a peer-reviewed source), study type (a review, meta-analysis, commentary, letter to the editor, editorial report, or other non-empirical article), no VR was used (a computer generated environment was not used or there was no interactivity with the environment), population (the sample did not include healthy human participants), task (the methods did not include participation in a sport or a physical exercise that used equipment related to a sport or sports training), game (the task was based wholly on an exergame/active videogame), rehabilitation (the purpose of the task was to rehabilitate those with physical injury), and measure (performance, physiological, or psychological outcomes were not the primary measures).

${ }^{1}$ Cohen's kappa for the decisions to exclude or include based on title and abstract (Step 1) was $\kappa=.64$ and based on review of full article (Step 2) was $\kappa=.69$, both of which fall within the guidelines for substantial agreement. Full agreement was reached at each step following discussion. 
Following the screening and selection process, 20 articles were included for full review. Of these articles, 18 were published in journals with journal citation metrics reported by the Web of Science database. The mean impact factor (based on the most recent year) was 2.21 (range $=0.06$ to $4.47, S D=1.21$ ) indicating that the journals were largely of good quality although with some exceptions. Consistent with this interpretation, the journal rankings varied evenly across the full spectrum of Q1 $(n=5), \mathrm{Q} 2(n=5), \mathrm{Q} 3(n=4)$, and Q4 $(n=4)$. The articles were coded by four authors and coding decisions were cross-checked. Articles were coded for characteristics related to the study (aims, type, location, conditions/groups, outcome measures, key findings), participants (sample size, age, experience with sport), virtual reality technology (task type, system, display features, point-of-view, others in the environment, immersion/presence measures), and sport task (type).

\section{Defining Virtual Reality in Sport}

VR when applied to sport may be defined as instances when individuals are engaged in a sport that is represented in a computer-simulated environment which aims to induce a sense of being mentally or physically present and enables interactivity with the environment. This definition highlights the computer-simulated nature and interactivity of the virtual environment, which are key element of more general definitions of VR (e.g., Baños et al. 2000; Sherman and Craig 2002). It also aims to highlight the application of VR to sport from the perspective of the user (athlete). Realistic responses to virtual environments are suggested to occur when the system induces a sense of presence and the perception that the events are actually occurring (Slater 2009). In this respect, it is important that VR uses a computergenerated environment because this is a key feature that allows for interactivity and the perception of presence (Baños et al. 2000; Sherman and Craig 2002). In other words, the virtual environment or elements within it will move or change in response to the actions of the athlete. However, the method by which the virtual environment is presented to the athlete should not be specified in the definition because it might impose technological limitations to 
the application of VR to sport (see Steuer 1992).

In many applications outside of sport, the virtual environment is displayed using a Computer Automatic Virtual Environment (CAVE) or Head Mounted Display (HMD). The CAVE is composed of a large cube made up of display screens that the user physically enters to become surrounded by the virtual environment. A HMD is a wearable device that covers the eyes and thus removes vision of the outside world. It has one or more small screens on which the virtual world is viewed in stereovision with a wide field of view. The HMD is combined with head tracking to allow the user to view areas of the virtual environment that are outside of the immediate field of view by turning their head. Being a smaller, more portable, and a more affordable system, the HMD is more popular than the CAVE, although both may be regarded as sharing the same key features of an immersive system (Slater, 2009).

However, the potential applications for using CAVE and HMD systems can be limited for some types of sports. A HMD may be impractical or potentially dangerous for some sports. For example, running a race on a treadmill using a HMD can be hazardous because vision of the moving treadmill is removed. The head movements and sweating of the athlete can also make the HMD uncomfortable to wear. Indeed, in no studies identified in this review was a HMD system used despite researchers consistently using the term virtual reality to describe their approach. The most common approach was a two dimensional depiction of the virtual environment using a computer screen or a projector. A computer screen or projector has the advantages of ease of use and practicality with sport but may induce less presence than a HMD or CAVE system. Further research is required to determine if there are significant difference in presence when a computer screen or projector is used.

Several instances can be identified in which researchers used methodology that approximated the proposed definition of VR applications to sport. For example, some researchers have used a visual display that shows a video of a real environment (e.g., Plante et al. 2006). Feltz, Kerr, Irwin and colleagues (e.g., Feltz et al. 2011) conducted a series of studies 
that investigated the Köhler motivation gain effect with a plank exercise task. These studies showed the participant via a video (i.e., not a computer-generated avatar) and included a second individual shown on a second visual display without any interaction. Videos of real environments and people may have potential for VR applications to sport but they must include elements of interactivity to fulfil the proposed definition of VR. Similarly, other researchers have used computer-generated environments to examine baseball batting (Ranganathan and Carlton 2007), handball goalkeeping (Vignais et al. 2015), and soccer goalkeeping (Stinson \& Bowman, 2014) but these did not allow for any interactivity with the environment and were not included in the review. Thus, the present review was focussed more specifically on interactive VR applications to sport. In some cases, it was also found that researchers used a non-animated avatar against a blank screen (e.g., Briki et al. 2013), but these do not meet the proposed definition because the methods did not simulate a real environment.

Another important consideration for interactive VR applications to sport is the distinction between sport, exercise, and exergaming. Sport may be defined as an activity that requires motor skill and/or hand-eye co-ordination combined with physical exertion and includes rules and elements of competition (Australian Bureau of Statistics 2008). Exercise, used synonymously with physical exercise, is a structured activity that may include repetitive elements that is performed to maintain or improve physical fitness (Australian Bureau of Statistics 2008). Exergame/active videogame is a videogame played on commercial game console systems (e.g., Xbox, Wii, PlayStation) that combines gameplay with physical movements that are more than sedentary behaviour (Kim et al. 2014). Exercise and exergames together represent a more general case of enhancing physical activity and may not necessarily be based on a sport.

Exercises or exergames that are not based on a sport clearly do not represent instances of VR applications to sport even if they incorporate a virtual environment. However, investigators have used sport-related computer games, particularly those that run on a games 
console, in research. Console games based on sports have been used to examine skill acquisition and transfer in children (Reynold et al. 2014) and adults (Tirp et al. 2015). However, these applications lacked an appropriate exertion interface (e.g., participants ran on the spot to simulate running in the game) or essential sporting equipment (e.g., no darts were used in a dart game) and these aspects can make the task substantially different to performing the sport in real life. VR has also been applied to exercise and improving physical fitness. In several studies, researchers have used sport-related tasks such as cycling, running, and rowing (e.g., Murray et al. 2016). These applications have relevance to sport performance particularly because many of these studies have introduced elements of competition or pressure to meet team goals.

\section{A Conceptual Framework for the Application of Virtual Reality to Sport}

The application of VR to sport has taken many forms, with various types of sport tasks, VR technologies, and types of athletes used in the research. Some researchers have examined questions relating to the use of VR technology itself, such as comparing outcomes when using VR and not using VR (e.g., Annesi and Mazas 1997; Legrand et al. 2011; Mestre et al. 2011; Plante et al. 2003a), the effects of immersion in the virtual environment (Ijsselsteijn et al. 2004; Vogt et al. 2015), and differences between computer-controlled and real virtual competitors (Snyder et al. 2012). In contrast, other researchers have used VR technology as part of a methodology to answer more general questions about factors related to sport performance. For example, Oliveira et al. (2015) used a virtual partner as a means to compare the effects of selfselected and externally imposed exercise intensity.

We developed a broad conceptual model that summarises and provides a framework to interpret the research conducted to date. As shown in Figure 1, the VR system results in outcomes that occur concurrently or following engagement in the VR sport task. The VR system is composed of four components. These are the VR environment, the sport task, the athlete, and the non-VR environment Research on VR applications to sport have largely 
focussed on only the first three of these components. The VR environment is the unique component for VR applications to sport and is the focus of most research. The second component, the sport task used, will differ according to the application and can vary between endurance type sports or skill-based sports. The third component relate to characteristics of the athlete, such as skill level and competitiveness. The characteristics of the athlete may act independently or they may interact with other elements of the VR system to influence outcomes. The fourth component encompasses those aspects of the real-world environment in which the athlete completes the task. Ambient temperature, humidity, and time of day are among the relevant factors that can be present and influence outcomes. Finally, all four elements of the VR system will produce outcomes that emerge on an ongoing basis when performing the sport task (concurrent outcomes) or they may emerge at a later time (posttask outcomes). The posttask outcomes may be short-term or long-term.

The four components of the VR system share elements in common with other models applied to sport and exercise psychology. For example, Tenenbaum and Hutchinson (2007) proposed that perceived effort and effort tolerance are determined by the individual (e.g., dispositions, task familiarity, demographic characteristics), the task (e.g., intensity, duration), and the environmental conditions (e.g., social, physical features) that are present in a given situation. These conditions are analogous to the three non-VR components of the VR system as presented in Figure 1. Such a similarity is to be expected because VR aims to simulate a real environment. However, research on VR applications to sport have not yet examined the effects of the real (non-VR) environment on performance. Instead, attention has been directed towards variables related to the virtual environment, such as immersion, presence, and interactivity with virtual others. Research supporting the conceptual framework depicted in Figure 1 is presented below.

\section{The Virtual Reality System}

Virtual Reality Environment and Task Factors. The first two components, the VR 
environment and sport task, may be considered together because they can be closely linked. For example, a rower may complete a time trial using a rowing ergometer. However, the ergometer is merely the exertion interface. It is transformed into a virtual boat such that pulls on the ergometer handle are depicted as movements of the virtual oars through the water. Increasing exertion on the task (e.g., rowing at a higher intensity) will be reflected in changes in the virtual environment (e.g., faster movement through the water and passing scenery). Thus, performance and other factors related to the task will influence the virtual environment and this relationship can be reciprocal.

Research has shown that several characteristics of the VR environment and the task influence outcomes. A summary of the methodological approaches used to create the VR environment and task is provided in Table 1. As can be seen, the sport tasks used most often have been cycling and running, but rowing, weightlifting, and golf have also been examined. Cycling, running, and rowing are sports that contain elements of endurance and persistence. These sports are also relatively easily to translate into a virtual environment. The exertion interface of the treadmill or ergometer can readily monitor information with regards to the speed and other performance elements (e.g., cadence) and translate this information into virtual movements. Interactivity is further enhanced by including directional controls although few VR systems have been used which have this capability.

The VR software and display equipment used in research has varied from commercially available products to those that are custom made. The virtual environment is typically displayed on computer screens or projected against a wall. A larger display or the inclusion of more multimodal elements of the environment will increase the sense of immersion in the virtual world (Vogt et al. 2015) and this can influence performance. Using a more immersive virtual environment during a cycling task (i.e., showing the track from the point of view of the rider versus from a birds eye view) has increased motivation and the speed of cycling in participants (Ijsselsteijn et al. 2004). Using a virtual running task, over a third of participants 
have reported that the immersion induced by the VR environment is an important motivating feature (Nunes et al. 2014). There might be a dose dependent relationship between the level of immersion induced by the VR system and the magnitude of the resulting outcomes.

The presence of others in the virtual environment has also emerged as an important feature of the VR environment. Indeed, the presence of others may be even more important than the capability of the VR system to induce feelings of immersion or presence. In a survey study examining golf play in a virtual environment, Lee et al. (2013) distinguished between two types of presence: telepresence or the feeling of being physical immersed in the virtual environment and social presence or the feeling of being with and communicating with others in the virtual environment. Social presence was shown to play a more important role in perceived enjoyment, perceived value, and behavioural intentions than telepresence. Further, unlike social presence, telepresence did not significantly predict any of these outcomes.

The presence of others has also influenced motivation and performance for aerobic sport tasks. Using a running task, Nunes et al. (2014) reported that participants preferred to run in the presence of virtual others than to run on the virtual course alone (Nunes et al. 2014). Irwin et al. (2012) examined the Köhler motivation gain effect while participants cycled in a virtual environment. Participants cycled at an intensity of 65\% of heart rate reserve for as long as they felt comfortable. Different groups of participants completed trials while cycling in the virtual environment alone or at the same time as another person (a confederate) who the participant was informed had performed moderately better than they did in a baseline trial. Cycling with the other person was either in a conjunctive situation (a "team score" would be based on the rider who quit the task first) or a coactive situation (no team partnership). Task persistence was higher in the coactive situation than when cycling alone. Moreover, a further enhancement of persistence was observed in the conjunctive situation, suggesting motivational gains when performing a VR-based sport in a team situation.

In the study by Irwin et al. (2012), the confederate was shown via a video loop on 
another screen and not in the VR environment. Murray et al. (2016) also examined the Köhler motivation gain effect in which the team mate was present as a virtual partner in the virtual environment. Female participants novice to rowing completed a rowing trial in the presence of a virtual team mate in a conjunctive situation (the shortest distance rowed over a 9 min trial would count as the team score) or in the VR environment alone. Prior to the trial, participants were informed that the team mate had rowed $40 \%$ longer than them in an initial baseline row. A Köhler motivation gain effect was found in that participants rowed further and had a higher heart rate in the presence of a team mate than when rowing in the VR environment alone. Moreover, the conditions did not differ in felt arousal, positive feelings, or ratings of perceived exertion. The latter finding suggests that performance improvements can be induced by a virtual partner in the absence of negative psychological costs.

The presence of others in a virtual environment can be used to more directly induce a pressure to perform in a competitive situation. Using a sample of older adults, AndersonHanley et al. (2011) compared cycling through a virtual course either alone or in the presence of on-screen rider avatars. In the latter condition, participants were explicitly asked to outpace the avatars. The introduction of the on-screen avatars increased cycling power output when compared to solo cycling condition. However, this effect was observed only in participants who were classified as high in competitiveness based on a self-report questionnaire. A limitation of this study was that all participants completed the solo cycling condition first and the competitive situation second. Nevertheless, the findings suggest that competitiveness is an important moderating factor in responses to VR.

Similar outcomes to Anderson-Hanley et al. (2011) were reached in a study by Snyder et al. (2012) who compared two competitive situations while participants cycled in a VR environment. In the virtual condition, the participants were informed that the avatar of the other rider was controlled by the computer. In a live rider condition, the participants were introduced to a confederate and were informed that the avatar speed was controlled by the cycling speed of 
the confederate. Cycling performance, measured as watts generated, was higher for the live rider condition than in the virtual rider condition. Again, this difference emerged only in participants high in competitiveness. No differences between the rider conditions emerged for participants low in competitiveness.

Competitive situations can be constructed within a virtual environment in various ways. Nunes et al. (2014) devised three competitive modes based on whether participants competed against themselves (i.e., a prior performance), against an individual chosen for them who is superior, or against any individual chosen by the participant. Using a VR running task, all types of competitive situations enhanced physical exertion (as measured by heart rate) and self-reported motivation when compared to running on the virtual course alone. Evidence was also found that participants who were not initially competitive still felt pressure to outperform the on-screen avatars. However, similar to the conclusions reached by Anderson-Hanley et al. (2011) and Snyder et al. (2012), participants who had a stronger preference for competitive situations showed the highest task performance.

A different approach to the use of another individual in the virtual environment was reported by Oliveira et al. (2015). Participants completed two conditions of a VR cycling task. In one condition, the participant self-selected the intensity of the cycling trial. In the other condition, participants were asked to follow a virtual cyclist. The virtual cyclist was set to a speed that matched the self-selected intensity condition. No significant differences were found between conditions on physiological effort or affective responses. Typically, an externally imposed intensity results in an increase in negative affect. The findings thus suggest that this affective "cost” is mitigated when participants match the imposed pace of a virtual partner. However, further research is required to confirm these findings. For example, order effects may have been a factor because all participants completed the self-selected condition first and followed by the externally imposed intensity condition.

User (Athlete) Factors. The third component of the VR system is the athlete who is 
engaging in the virtual sport. The characteristics of the athlete user have the potential to mediate or moderate the effects of VR on performance and psychological outcomes. Athlete user factors may include physical characteristics, expertise and experience, and psychological characteristics. As shown in Table 2, the participants recruited in research to date have been relatively homogenous. The typical participant has been a young adult sampled from Western countries who are novice to the sport. It has been suggested that using novices is advantageous because it results in a sample that is more physiologically equivalent and their performance is less likely to be influenced by prior learning (Hoffman et al. 2014). However, it reduces the generalisation of findings to participants that are younger or older or who compete at the elite level.

It is surprising that most studies have not reported comparisons between males and females given the documented gender differences in not only sport performance but also in experience with computerised environments (e.g., computer games). Plante, Aldridge et al. (2003a) included gender as a factor when examining the effects of VR on mood during cycling. Females showed a larger difference in reported relaxation between the VR alone (no cycling) and both the cycling alone and cycling with VR conditions when compared to males. Plante, Frazier et al. (2003b) also used a cycling task and reported gender differences in ratings of energy. Males reported higher energy when cycling alone, cycling with VR, or experiencing VR alone than in a baseline control condition that did not involve VR or cycling. In contrast, females reported more energy in cycling alone or cycling with VR than when VR was used without cycling or in the baseline condition. While preliminary, there is some suggestion that females may be influenced more by the VR environment than males.

The preferences of the individual user may be an important psychological factor that moderates outcomes. Legrand et al. (2011) assigned participants to either a cycling task alone (no VR input), a self-selected VR task (either jogging or cycling), or an externally imposed VR task (either jogging or cycling). All conditions improved positive affect and reduced negative 
affect when assessed by pre- and post-task subjective measures. The in-task subjective measures showed that participants in the self-selected VR task reported higher pleasure than the cycling alone or the externally imposed VR task, which themselves did not differ. Autonomy or the appropriate matching of an individual to a preferred sport may thus be important for mood benefits when using VR. As noted above, individual preferences for task intensity may be another factor in that using VR technology may reduce the negative impact of performing at an externally imposed intensity (Oliveira et al. 2015).

Non-VR Environment Factors. The final component of the VR system, the real-world environment, has received no attention in research conducted to date. Researchers have used a controlled indoor environment and have kept key variables like temperature, humidity, and time of day constant or allowed them to vary at random. Tenenbaum and Hutchinson (2007) noted that the environment can be divided into physical and social components and a similar distinction can be made here. In particular, based on research showing that the presence of others in the virtual environment can influence performance and psychological states, it would be expected that the presence of others in the real environment will also have an influence. Further research is required to examine the effects of environmental factors and to determine the relative strength of these factors when present virtually versus when present in reality.

\section{Concurrent and Posttask Outcomes}

A summary of the key research aims and outcomes is shown in Table 3. The majority of the outcomes have been observed concurrently with the task, but some have been observed posttask (i.e., short-term and long-term effects; see Figure 1). Concurrent outcomes are those that influence ongoing behaviour (e.g., performance, persistence, affective states, perceived exertion). For example, VR tasks that induce competitiveness may induce short-term increases in performance if the individual is running at a pace slower than a virtual competitor (Nunes et al. 2014). Posttask outcomes will influence behaviour at a later time and are thus independent of the ongoing interaction with the VR system (e.g., meeting performance goals, competition 
outcomes). For instance, Annesi and Mazas (1997) showed that an exercise program that used a VR cycling task increased adherence to an exercise program relative to cycling alone.

Outcomes may also be divided into those related to task performance, physiological effects, and psychological processes. As shown in Table 3, performance outcomes in past research include adherence (Anderson-Hanley et al. 2014; Annesi and Mazas 1997; Irwin et al. 2012), distance travelled or speed in the virtual environment (Hoffman et al. 2014; Ijsselsteijn et al. 2004; Murray et al. 2016; Nunes et al. 2014; Snyder et al. 2012), physical intensity exerted (Anderson-Hanley et al. 2011; Chen et al. 2015; Snyder et al. 2012), in-task persistence (Irwin et al. 2012), and strategy (Hoffman et al. 2014). Physiological outcomes have included heart rate (Nunes et al. 2014; Snyder et al. 2012), oxygen consumption and blood lactate level (Oliveira et al. 2015), muscle fatigue (Chen et al. 2015), and electroencephalogram amplitude and frequency (Vogt et al. 2015). Psychological outcomes may relate to behavioural intentions (Lee et al. 2012), cognitive functions (Anderson-Hanley et al. 2012), motivation (Ijsselsteijn et al. 2004; Nunes et al. 2014), perceived pressure (Ijsselsteijn et al. 2004), attentional focus (Baños et al. 2016; Mestre et al. 2011), and various positive and negative feeling states.

The application of VR to sport has resulted in several beneficial outcomes. When compared to control conditions, tasks that incorporate VR have shown improved adherence (Annesi and Mazas 1997), better race strategy performance (Hoffman et al. 2014), higher cognitive functioning (Anderson-Hanley et al. 2012), improved mood and reduced tiredness (Plante et al. 2003b), increased workload (Chen et al. 2015), and higher enjoyment (Mestre et al. 2011; Murray et al. 2016). However, the control condition used in most research has involved performance of the sport on its own. This approach may be questioned because it does not control for the presence of an external stimulus during the task. It is possible that the VR environment may produce its effects because it distracts and diverts attention away from the task (Baños et al. 2016; Mestre et al. 2011), rather than because it induces a sense of presence or includes elements of interactivity, which are the key features of a VR environment. 
It is also noteworthy that better performance or psychological outcomes have not always resulted when VR is used (e.g., Lee et al. 2012; Legrand et al. 2011) suggesting that other factors may moderate its effectiveness. As noted above and shown in Table 3, these factors may relate to the VR system or user, such as level of immersion (Ijsselsteijn et al. 2004), competitiveness (Anderson-Hanley et al. 2011; Nunes et al. 2014; Snyder et al. 2012), social presence (Irwin et al. 2012; Lee et al. 2012; Murray et al. 2016), self-selection of tasks (Legrand et al. 2011), attentional focus (Mestre et al. 2011), and the mood altering effects of the task itself (Plante et al. 2003b).

Performance and psychological outcomes may result from the additive or interactive effects of the VR system. For example, a high level of immersion will enhance motivation and performance (Ijsselsteijn et al. 2004). However, immersion may be increased in different ways. It can be enhanced by using a more realistic VR environment as done by Ijsselsteijn et al. (2004). It can also be enhanced if the individual has a high trait level to feel a greater sense of presence. Interactions between external and individual factors may also influence outcomes. For instance, the introduction of a virtual competitor (VR environment factor) can increase performance (Nunes et al. 2012), although the increase may only be observed if the individual is competitive (athlete factor) as demonstrated in research (Anderson-Hanley et al. 2011; Snyder et al. 2012). Further research is required to examine other interactive effects.

\section{Future Research Directions and Recommendations}

The present review has highlighted issues that warrant further investigation. Most research to date has focussed on VR tasks that involve aerobic sports (cycling, running, and rowing). More research is required on the effectiveness of a VR environment for learning or improving the mechanics of skill acquisition and performance in skill-based sports (see Sigrist et al. 2015 for an example). The capacity for VR environments to be created in specific and reproducible ways can allow for the training and assessment of skills and decision-making processes. Some of the factors identified as important with aerobic sports (e.g., attentional 
focus, competitiveness) may also be important in skill-based sports when VR is used.

Research is required to examine the generality of effects with VR. Studies should include more diverse populations, particularly experienced and elite athletes, children and the elderly. In addition, research has also not examined relationships between performance in VR and real world environments. Identifying how the two situations differ and how they are the same could inform how VR influences performance and psychological states. The transfer of performance from the virtual environment to the real world has also not been tested, yet it seems an essential requirement if VR is to be used as a training approach for sport.

Further research is required that aims to directly manipulate psychological processes. For example, it has been suggested that VR environments induce a dissociative attentional focus and that this may be related to affective responses (Mestre et al. 2011). Baños et al. (2016) applied this concept by asking overweight and normal weight children to walk on a treadmill while focussing their attention on their physical feelings or while focusing their attention on a virtual environment. Ratings of enjoyment were higher for the VR condition than the self-focused condition, although there were no differences in perceived exertion or feeling states. The findings are promising but are in need of replication and extension. Past research with non-VR tasks has also found that an external associative focus enhances sport and exercise outcomes (e.g., Neumann and Heng 2011; Neumann and Piercy, 2013). An external associative focus involves focussing on the effects of movements on the environment and the achievement of task goals (Neumann and Brown, 2013; Stevinson and Biddle, 1999). Future research could thus use VR to induce an external associative focus and examine its effectiveness in enhancing performance.

Further research is required to elucidate what factors are relevant to performance and affective outcomes. Research using multiple measures or manipulations may be particularly useful to determine the relative amounts of variance in performance attributed to different aspects of the VR environment. In addition, different features of the sport task should be 
varied. For example, intensity may be a particularly salient factor for aerobic sports. A higher intensity level may switch attentional focus towards internal physiological states (Stevinson and Biddle, 1999) and result in individuals focusing attention away from the VR environment. It may be possible to enhance attentional focus on the virtual environment by requiring participants to follow a virtual partner as done by Oliveira et al. (2015).

Finally, the nature of computer-based interactions is becoming more diverse and with a greater amount of overlap between the different forms of technology and their applications. The present review applied a definition of VR that required interactivity with the virtual environment. However, it is acknowledged that researchers are developing and testing systems that employ a virtual environment that the athlete responds to, even though the behaviour of the athlete does not affect any feature of the environment. For example, goalkeeping skills in penalty shots has been examined in both handball (Vignais et al. 2015), and soccer/football (Stinson \& Bowman, 2014). In these applications, the goalkeeper viewed a virtual environment depicting an individual shooting a penalty and was required to move their body in the predicted direction of the ball. Their movements did not influence the action of the virtual penalty kick taker (e.g., moving too early had no effect). Another instance that resembles VR is the use of augmented reality. In such applications, a user has an indirect view of a physical, real-world environment in which computer-generated input is added to. The input may be visual, auditory, or other senses. This blending of real and virtual environmental elements has yet to be extensively examined in sporting applications.

Based on the present review, recommendations can also be made to ensure appropriate methodology and report in studies. It is recommended that researchers:

1. Use the term virtual reality accurately and consistently in reference to studies that have employed VR technologies according to accepted definitions such as the one proposed here. The term should not be confused with exergames, which refers to the more general case of enhancing physical activity via interactive computer game play. If interactivity with the virtual 
environment is a particular feature that is to be highlighted, such as in the present review, the term interactive VR may be used.

2. Report participants prior experience with VR in general and with the specific VR system because experience level may be an important factor that influences outcomes.

3. Use a measure of immersion or presence as a standard part of the protocol because these aspects are a core feature of VR and the level of immersion has emerged as an important factor that influences outcomes (Ijsselsteijn et al. 2004; Vogt et al. 2015). Such measures include the Reality Judgement and Presence Questionnaire (Baños et al. 2000) and the Presence Questionnaire (Witmer and Singer, 1998).

4. Provide full details of the VR system that is used. These details include the name of the system or software used, the participant point of view, the presence of others in the VR environment, the presence of sounds in the VR environment, and the mechanisms through which the participant interacts with the VR environment.

5. Report on relevant procedures that are important psychologically, such as whether participants had choice over the type of VR task or discrete elements within the task.

\section{Conclusions}

This review identified research studies that have investigated the application of VR to sport. The research findings to date indicate that VR can be a promising adjunct to existing real world training and participation in sport. A VR-based system for training and participation has several advantages such as enabling athletes to train regardless of weather conditions, providing a means to compete with others in a different geographic location, and allowing precise and replicable control over features of the virtual environment. Future research would benefit from a theoretical framework of VR application to sport. The present review has shown that the characteristics of the individual user and system are important factors that can influence a range of performance, physiological, and psychological outcomes. By understanding the experience of when individuals are engaged in sport within a VR 
environment, researchers, coaches, and athletes will able to use the technology for the benefit of athletes and society in general. 


\section{References}

Anderson-Hanley C, Arciero PJ, Barcelos N, Nimon J, Rocha T, Thurin M, Maloney M (2014) Executive function and self-regulated exergaming adherence among older adults. Front Hum Neurosci 8:989. doi:10.3389/fnhum.2014.00989

Anderson-Hanley C, Arciero PJ, Brickman AM, Nimon JP, Okuma N, Westen SC, Molly EM, Pence BD, Woods JA, Kramer AF, Zimmerman EA (2012) Exergaming and older adult cognition: A cluster randomized clinical trial. Am J Prev Med 42:109-119.

doi:10.1016/j.amepre.2011.10.016

Anderson-Hanley C, Snyder AL, Nimon JP, \& Arciero PJ (2011) Social facilitation in virtual reality-enhanced exercise: Competitiveness moderates exercise effort of older adults. Clin Interv Aging 6:275-280. doi:10.2147/cia.s25337

Annesi JJ, Mazas J (1997) Effects of virtual reality-enhanced exercise equipment on adherence and exercise-induced feeling states. Percept Motor Skill 85:835-844. doi:10.2466/pms.1997.85.3.835

Australian Bureau of Statistics (2008) Defining sport and physical activity, a conceptual model. ABS Catalogue No. 4149.0.55.001.

Baca A, Dabnichki P, Heller M, Kornfeind P (2009) Ubiquitous computing in sports: a review and analysis. J Sport Sci 27:1335-1346. doi:10.1080/02640410903277427

Baños RM, Botella C, Garcia-Palacios A, Villa H, Perpiñá C, Alcañiz M. (2000). Presence and reality judgment in virtual environments: A unitary construct? Cyberpsychol Behav 3:327-335. doi:10.1089/10949310050078760

Baños RM, Escobar P, Cebolla A, Guixeres J, Alvarez J, Francisco J, Botella C (2016) Using virtual reality to distract overweight children from bodily sensations during exercise. Cyberpsychol Behav Soc Netw. 19:115-119. doi:10.1089/cyber.2015.0283

Briki W, Den Hartigh RJR, Markman KD, Micallef J, Gernigon C (2013) How psychological momentum changes in athletes during a sport competition. Psychol Sport Exerc 
14:389-396. doi:10.1016/j.psychsport.2012.11.009

Chen KB, Ponto K, Tredinnick RD, Radwin RG (2015) Virtual exertions: Evoking the sense of exerting forces in virtual reality using gestures and muscle activity. Hum Factors 57:658-673. doi:10.1177/0018720814562231

Feltz DL, Kerr NL, Irwin BC (2011) Buddy up: The Köhler effect applied to health games. J Sport Exercise Psy 33:506-526. doi:10.1123/jsep.33.4.506

Guy S, Ratzki-Leewing A, Gwadry-Sridhar F (2011) Moving beyond the stigma: Systematic review of video games and their potential to combat obesity. Int J Hypertens Article ID 179124. doi:10.4061/2011/179124

Hoffmann CP, Filippeschi A, Ruffaldi E, Bardy BG (2014) Energy management using virtual reality improves 2000-m rowing performance. J Sport Sci 32:501-509. doi:10.1080/02640414.2013.835435

Ijsselsteijn W, de Kort Y, Westerink J, de Jager M, Bonants R (2004) Fun and sports: Enhancing the home fitness experience. Lect NotesComput Sc 3166:46-56. doi:10.1007/978-3-540-28643-1_8

Irwin BC, Scorniaenchi J, Kerr NL, Eisenmann JC, Feltz DL (2012) Aerobic exercise is promoted when individual performance affects the group: A test of the Kohler motivation gain effect. Ann Behav Med 44:151-159. doi:10.1007/s12160-012-9367-4

Kim SY, Prestopnik N, Biocca FA (2014) Body in the interactive game: How interface embodiment affects physical activity and health behavior change. Comput Hum Behav 36:376-384. doi:10.1016/j.chb.2014.03.067

Larsen LH, Schou L, Lund HH, Langberg H (2013) The physical effect of exergames in healthy elderly - A systematic review. Games Health J 2:205-212. doi:10.1089/g4h.2013.0036

Laver KE, George S, Thomas S, Deutsch JE, Crotty M (2015) Virtual reality for stroke rehabilitation. Cochrane Database of Systematic Reviews, Issue 2. Art. No.: 
CD008349. doi:10.1002/14651858.CD008349

Lee HG, Chung S, Lee WH (2012) Presence in virtual golf simulators: The effects of presence on perceived enjoyment, perceived value, and behavioral intention. New Media Soc 15:930-946. doi:10.1177/1461444812464033

Legrand FD, Joly PM, Bertucci WM, Soudain-Pineau MA, Marcel J (2011) Interactive-Virtual Reality (IVR) exercise: An examination of in-task and pre-to-post exercise affective changes. J Appl Sport Psychol 23:65-75. doi:10.1080/10413200.2010.523754

Liberati A, Altman DG, Tetzlaff J, Mulrow C, Gøtzsche PC, Ioannidis JPA, Clarke M, Devereaux PJ, Kleijnen J, Moher D (2009) The PRISMA statement for reporting systematic reviews and meta-analyses of studies that evaluate healthcare interventions: explanation and elaboration. Br Med J 339:b2700. doi:10.1136/bmj.b2700

Meline T (2006) Selecting studies for systematic review: Inclusion and exclusion criteria. Contemp Issues Commun Sci Disord 33:21-27.

Mestre DR, Ewald M, Maiano C (2011) Virtual reality and exercise: Behavioral and psychological effects of visual feedback. St Heal T 167:122-127. doi:10.3233/978-160750-766-6-122

Meyerbröker K, Emmelkamp PMG (2010) Virtual reality exposure therapy in anxiety disorders: a systematic review of process-and-outcome studies. Depress Anxiety 27:933-944. doi:10.1002/da.20734

Mueller FF, Stevens G, Thorogood A, O’Brien S, Wulf V (2007) Sports over a distance. Pers UbiquitComput 11:633-645. doi:10.1007/s00779-006-0133-0

Murray EG, Neumann DL, Moffitt RL, Thomas PR (2016) The effects of the presence of others during a rowing exercise in a virtual reality environment. Psychol Sport Exerc 22:328-336. doi:10.1016/j.psychsport.2015.09.007

Neumann DL, Brown J (2013) The effect of attentional focus strategy on physiological and motor performance during a sit-up exercise. J Psychophysiol 27:7-15. 
doi:10.1027/0269-8803/a000081

Neumann DL, Heng S (2011) The effects of associative and dissociative attentional focus strategies on muscle activity and heart rate during a weight training exercise. $\mathrm{J}$ Psychophysiol 25:1-8. doi:10.1027/0269-8803/a000011

Neumann DL, Piercy A (2013). The effect of different attentional strategies on physiological and psychological states during running. Aust Psychol 48:329-337. doi:10.1111/ap.12015

Nunes M, Nedel L, Roesler V (2014) Motivating people to perform better in exergames: Competition in virtual environments. In Proceedings of the $29^{\text {th }}$ Annual ACM Symposium on Applied Computing (pp. 970-975). New York, NY: ACM. doi:10.1145/2554850.2555009

Oliveira BRR, Deslandes AC, Nakamura FY, Viana BF, Santos TM (2015) Self-selected or imposed exercise? A different approach for affective comparisons. J Sports Sci 33:777_ 785. doi:10.1080/02640414.2014.968191

Peng W, Crouse JC, Lin JH (2013) Using active video games for physical activity promotion: A systematic review of the current state of research. Health Educ Behav 40:171-192. doi:10.1177/1090198112444956

Plante TG, Aldridge A, Bogden R, Hanelin C (2003a) Might virtual reality promote the mood benefits of exercise? Comput Hum Behav 19:495-509. doi:10.1016/S07475632(02)00074-2

Plante TG, Cage C, Clements S, Stover A (2006) Psychological benefits of exercise paired with virtual reality: Outdoor exercise energizes whereas indoor virtual exercise relaxes. Int J Stress Manage 13:108-117. doi:10.1037/1072-5245.13.1.108

Plante TG, Frazier S, Tittle A, Babula M, Ferlic E, Riggs E (2003b) Does virtual reality enhance the psychological benefits of exercise? J Hum Movement Stud 45:485-507. doi:10.1037/e314842004-001 
Ranganathan R, Carlton LG (2007). Perception-action coupling and anticipatory performance in baseball batting. J Motor Behav 39:369-380. doi:10.3200/JMBR.39.5.369-380

Reynolds JE, Thornton AL, Lay BS, Braham R, Rosenberg M (2014) Does movement proficiency impact on exergaming performance? Hum Movement Sci 34:1-11. doi:10.1016/j.humov.2014.02.007

Sherman WR, Craig AB (2002) Understanding virtual reality: Interface, application, and design. Elsevier, San Francisco

Sigrist R, Rauter G, Marchal-Crespo L, Riener R, Wolf P (2015) Sonification and haptic feedback in addition to visual feedback enhances complex motor task learning. Exp Brain Res 233:909-925. doi:10.1007/s00221-014-4167-7

Slater M (2009) Place illusion and plausibility can lead to realistic behaviour in immersive virtual environments. Philos T R Soc B 364:3549-3557. doi:10.1098/rstb.2009.0138 Snyder AL, Anderson-Hanley C, Arciero PJ (2012) Virtual and live social facilitation while exergaming: Competitiveness moderates exercise intensity. J Sport Exercise Psy $34: 252-259$.

Steuer J (1992) Defining virtual reality: Dimensions determining telepresence. J Commun 42:73-93. doi:10.1111/j.1460-2466.1992.tb00812.x

Stevinson CD, Biddle SJH (1999) Cognitive strategies in running: A response to Masters and Ogles (1998). Sport Psychol 13:235-236. doi:10.1123/tsp.13.2.235

Stinson, C., \& Bowman, D. A. (2014). Feasibility of training athletes for high-pressure situations using virtual reality. IEEE Transactions on Visualisation and Computer Graphics, 20, 606-615.

Tenenbaum G, Hutchinson JC (2007) A social-cognitive perspective of perceived and sustained effort. In G. Tenenbaum \& R. C. Eklund (Eds.), Handbook of sport psychology, 3rd edn. Wiley, New Jersey, pp 560-573

Tirp J, Steingrover C, Wattie N, Baker J, Schorer J (2015) Virtual realities as optimal learning 
environments in sport - A transfer study of virtual and real dart throwing. Psychol Test Assess Model 57:57-69.

Vignais N, Kulpa R, Brault S, Presse D, Bideau B (2015) Which technology to investigate visual perception in sport: Video vs. virtual reality. Hum Movement Sci 39:12-26. doi:10.1016/j.humov.2014.10.006

Vogt T, Herpers R, Scherfgen D, Strüder HK, Schneider S (2015) Neuroelective adaptations to cognitive processing in virtual environments: an exercise-related approach. Exp Brain Res 233:1321-1329. doi:10.1007/s00221-015-4208-X

Witmer BG, Singer MJ (1998) Measuring presence in virtual environments: A Presence Questionnaire. Presence-Teleop Virt 7:225-240. doi:10.1162/105474698565686 
Table 1

Characteristics of the task and virtual reality system of studies investigating virtual reality in sport

\begin{tabular}{|c|c|c|c|c|c|c|c|}
\hline Authors & Year & Task & Sport Equipment & VR Technology & VR Display & Point of View & Others in Environment \\
\hline Anderson-Hanley et al. & 2011 & Cycling & $\begin{array}{l}\text { Recumbent stationary } \\
\text { bicycle }\end{array}$ & Netathlon Riding Software & Laptop screen & Not specified & Some conditions \\
\hline Anderson-Hanley et al. & 2012 & Cycling & $\begin{array}{l}\text { Recumbent stationary } \\
\text { bicycle }\end{array}$ & Netathlon Riding Software & Laptop screen & Not specified & Yes \\
\hline Anderson-Hanley et al. & 2014 & Cycling & $\begin{array}{l}\text { Recumbent stationary } \\
\text { bicycle }\end{array}$ & Netathlon Riding Software & Laptop screen & Not specified & Yes \\
\hline Annesi and Mazas & 1997 & Cycling & $\begin{array}{l}\text { Stationary recumbent } \\
\text { bicycle }\end{array}$ & Tectrix VR bike & Screen & Not specified & Yes \\
\hline Baños et al. & 2016 & Walking & Treadmill & Commercial VR exergaming platform) & Projected & Third & Not specified \\
\hline Chen et al. & 2015 & Weightlifting & Dumbbells & $\begin{array}{l}\text { Cave Automatic Virtual Environment } \\
\text { (CAVE) }\end{array}$ & Projected & Not specified & No \\
\hline Hoffman et al. & 2014 & Rowing & Indoor rowing ergometer & Not specified & Screen & First & Not specified \\
\hline Ijsselsteijn et al. & 2004 & Cycling & Stationary racing bicycle & Tacx T1900 'i-magic' VR Trainer & Projected & First and third & Yes \\
\hline Irwin et al. & 2012 & Cycling & Stationary bicycle & Expresso fitness bike system & Screen & Not specified & Some conditions \\
\hline Lee et al. & 2012 & Golf & Golf ball and clubs & $\begin{array}{l}\text { Golfzon managed and operated virtual } \\
\text { golf simulator }\end{array}$ & Projected & First & Not specified \\
\hline Legrand et al. & 2011 & Running or cycling & $\begin{array}{l}\text { Treadmill and regular } \\
\text { bicycle ergometer }\end{array}$ & Tacx I-magic Fortius & Projected & Not specified & No \\
\hline Mestre et al. & 2011 & Cycling & Stationary bicycle & Tacx VR Trainer & Screen & Third & Yes \\
\hline Murray et al. & 2016 & Rowing & Indoor rowing ergometer & Netathlon 2 XF Software & Projected & Third & Yes \\
\hline Nunes et al. & 2014 & Running & Treadmill & Running Wheel & Screen & Third & Some conditions \\
\hline Oliviera et al. & 2015 & Cycling & Cycle ergometer & CompuTrainer 3D Software & Screen & Not specified & Yes \\
\hline Plante et al. & 2003a & Cycling & Stationary bicycle & $\begin{array}{l}\text { Trek Extreme Mountain Biking and Cycle } \\
\text { Fx ITS-1 with Ultra Coach VR Lite }\end{array}$ & Screen & Third & Yes \\
\hline Plante et al. & $2003 \mathrm{~b}$ & Cycling & Stationary bicycle & $\begin{array}{l}\text { Trek Extreme Mountain Biking and Cycle } \\
\text { Fx ITS-1 }\end{array}$ & Screen & Third & Yes \\
\hline Sigrist et al. & 2015 & Rowing & Indoor rowing ergometer & $\begin{array}{l}\text { Cave Automatic Virtual Environment } \\
\text { (CAVE) }\end{array}$ & Projected & Not specified & No \\
\hline Snyder et al. & 2012 & Cycling & $\begin{array}{l}\text { Recumbent stationary } \\
\text { bicycle }\end{array}$ & Cybercycle Expresso S3R & Screen & Third & Yes \\
\hline Vogt et al. & 2015 & Cycling & Cycle ergometer & Custom made & Projected & First & No \\
\hline
\end{tabular}

Note: $\mathrm{VR}=$ virtual reality. 
Table 2

Sample size and participant characteristics of studies investigating virtual reality in sport

\begin{tabular}{|c|c|c|c|c|c|c|}
\hline Authors & Year & $\mathrm{N}$ & Gender & Age (in years) & Experience Type & Location \\
\hline Anderson-Hanley et al. & 2011 & 14 & Both & $\begin{array}{l}M=78.51 \\
\text { Range }=60-99\end{array}$ & Novice & U.S.A. \\
\hline Anderson-Hanley et al. & 2012 & 79 & Both & $M=78.76$ & Novice & U.S.A. \\
\hline Anderson-Hanley et al. & 2014 & 30 & Both & $M=79.5$ & Novice & U.S.A. \\
\hline Annesi and Mazas & 1997 & 39 & Both & $M=37.7$ & Novice & U.S.A. \\
\hline Baños et al. & 2016 & 109 & Both & $\begin{array}{l}M=11.86 \\
\text { Range }=10-15\end{array}$ & Novice & Spain \\
\hline Chen et al. & 2015 & 11 & Both & $M=24.5$ & Novice & U.S.A. \\
\hline Hoffman et al. & 2014 & 15 & Males & $M=24.1$ & Novice & France \\
\hline Ijsselsteijn et al. & 2004 & 24 & Both & $M=41.3$ & Novice & Netherlands \\
\hline Irwin et al. & 2012 & 58 & Females & $M=20.54$ & Novice & U.S.A. \\
\hline Lee et al. & 2012 & 275 & Both & 80.4\% fell within 30-49 & Experienced & South Korea \\
\hline Legrand et al. & 2011 & 131 & Both & $M=19.31$ & Experienced & France \\
\hline Mestre et al. & 2011 & 6 & Not specified & Range $=19-25$ & Novice & France \\
\hline Murray et al. & 2016 & 60 & Female & $\begin{array}{l}M=20.20 \\
\text { Range = 18-30 }\end{array}$ & Novice & Australia \\
\hline Nunes et al. & 2014 & 12 & Both & $\begin{array}{l}M=33.91 \\
\text { Range = 22-52 }\end{array}$ & Novice & Brazil \\
\hline Oliviera et al. & 2015 & 17 & Male & $\begin{array}{l}M=31 \\
\text { Range 18-40 }\end{array}$ & Novice & Brazil \\
\hline Plante et al. & 2003a & 88 & Both & $\begin{array}{l}M=38.10 \\
\text { Range }=20-67\end{array}$ & Novice & U.S.A. \\
\hline Plante et al. & $2003 \mathrm{~b}$ & 121 & Both & $\begin{array}{l}M=18.58 \\
\text { Range }=17-27\end{array}$ & Novice & U.S.A. \\
\hline Sigrist et al. & 2015 & 24 & Both & $\begin{array}{l}M=26.1 \\
\text { Range }=21-33\end{array}$ & Novice & Switzerland \\
\hline Snyder et al. & 2012 & 23 & Females & $\begin{array}{l}M=19.2 \\
\text { Range }=17-22\end{array}$ & Novice & U.S.A. \\
\hline Vogt et al. & 2015 & 22 & Both & $M=30.27$ & Novice & Germany \\
\hline
\end{tabular}


Table 3

Characteristics of the design, aims, conditions, measures, and key findings of studies investigating virtual reality in sport

\begin{tabular}{|c|c|c|c|c|c|c|c|}
\hline Authors & Year & Study Design & Aims & Conditions & Measures & $\begin{array}{l}\text { Immersion/ } \\
\text { Presence } \\
\text { Measure }\end{array}$ & Key Findings \\
\hline Anderson-Hanley et al. & 2011 & $\begin{array}{l}\text { Quasi- } \\
\text { Experimental }\end{array}$ & $\begin{array}{l}\text { To evaluate the effect of social } \\
\text { facilitation and competitiveness on } \\
\text { cycling in older adults }\end{array}$ & $\begin{array}{l}\text { (1) Stationary cycling } \\
\text { with VR (2) Stationary } \\
\text { cycling with VR and on- } \\
\text { screen competitors }\end{array}$ & Competitiveness and cycling effort & No & $\begin{array}{l}\text { The introduction of competitor avatars } \\
\text { increased cycling intensity more for } \\
\text { competitive older adults than for those who } \\
\text { were less competitive }\end{array}$ \\
\hline Anderson-Hanley et al. & 2012 & Experimental & $\begin{array}{l}\text { To determine if virtual cycling would } \\
\text { result in greater executive function, } \\
\text { and increase brain-derived } \\
\text { neurotrophic growth factor }\end{array}$ & $\begin{array}{l}\text { (1) Stationary cycling } \\
\text { (2) Stationary cycling } \\
\text { with interactive VR } \\
\text { tours }\end{array}$ & $\begin{array}{l}\text { Executive function and other cognitive } \\
\text { function measures, BMI, body } \\
\text { composition, strength, energy } \\
\text { expenditure, and brain-derived } \\
\text { neurotropic factor }\end{array}$ & No & $\begin{array}{l}\text { VR cycling tours showed greater executive } \\
\text { functioning and neuroplasticity than } \\
\text { cycling on its own; VR cycling tours had a } \\
23 \% \text { relative risk reduction in mild } \\
\text { cognitive impairment }\end{array}$ \\
\hline Anderson-Hanley et al. & 2014 & Experimental & $\begin{array}{l}\text { To determine if higher executive } \\
\text { function would predict cycling } \\
\text { behaviour over a 3-month follow-up } \\
\text { period }\end{array}$ & $\begin{array}{l}\text { (1) Stationary cycling } \\
\text { (2) Stationary cycling } \\
\text { with interactive VR } \\
\text { tours }\end{array}$ & $\begin{array}{l}\text { Executive function, self-efficacy, } \\
\text { perceived benefits and barriers to } \\
\text { exercise, social support, motivation, } \\
\text { cognitive impairment, ,and physical } \\
\text { illness }\end{array}$ & No & $\begin{array}{l}\text { Exercise self-efficacy and declining } \\
\text { executive function at post-intervention } \\
\text { were associated with more frequent } \\
\text { exercise during follow-up }\end{array}$ \\
\hline Annesi and Mazas & 1997 & Experimental & $\begin{array}{l}\text { To test the effectiveness of VR on } \\
\text { increasing adherence, attendance, and } \\
\text { feeling states }\end{array}$ & $\begin{array}{l}\text { (1) Upright bicycle (2) } \\
\text { Recumbent bicycle (3) } \\
\text { Recumbent bicycle with } \\
\text { VR }\end{array}$ & $\begin{array}{l}\text { Attendance, adherence, exercise- } \\
\text { induced feelings, and self-motivation }\end{array}$ & No & $\begin{array}{l}\text { VR cycling was effective in maintaining } \\
\text { adherence to regular cycling; exercise- } \\
\text { induced feelings was not affected by VR } \\
\text { cycling }\end{array}$ \\
\hline Baños et al. & 2016 & $\begin{array}{l}\text { Quasi- } \\
\text { Experimental }\end{array}$ & $\begin{array}{l}\text { To determine if a VR walking task } \\
\text { creates attentional distraction from } \\
\text { bodily sensations in overweight } \\
\text { children }\end{array}$ & $\begin{array}{l}\text { (1) Group (overweight, } \\
\text { normal weight) (2) } \\
\text { Condition (no VR, VR) }\end{array}$ & $\begin{array}{l}\text { HR, attentional focus, exercise- } \\
\text { induced feelings, ratings of perceived } \\
\text { exertion, enjoyment, and preference }\end{array}$ & No & $\begin{array}{l}\text { VR decreased focus on bodily sensations } \\
\text { and increased external focus for overweight } \\
\text { children; enjoyment ratings were higher in } \\
\text { the VR condition }\end{array}$ \\
\hline Chen et al. & 2015 & Experimental & $\begin{array}{l}\text { To determine if VR improves } \\
\text { weightlifting performance and ratings } \\
\text { of perceived exertion }\end{array}$ & $\begin{array}{l}\text { (1) VR (no VR, 3-D } \\
\text { stereo, 2-D stereo) (2) } \\
\text { Weight of lift (low, } \\
\text { moderate, high) (3) } \\
\text { Height of lift (low, } \\
\text { moderate, high) }\end{array}$ & $\begin{array}{l}\text { Muscle fatigue, power frequency, } \\
\text { ratings of perceived exertion, and } \\
\text { perceived workload }\end{array}$ & No & $\begin{array}{l}\text { Bicep muscle activity and workload was } \\
\text { higher in both VR conditions than no VR } \\
\text { condition; ratings of perceived exertion did } \\
\text { not differ across conditions }\end{array}$ \\
\hline Hoffman et al. & 2014 & Experimental & $\begin{array}{l}\text { To determine if VR using an avatar to } \\
\text { train a race strategy would improve } \\
\text { energy management and race } \\
\text { outcomes }\end{array}$ & $\begin{array}{l}\text { (1) VR with no avatar } \\
\text { (2) VR with avatar using } \\
\text { a fast-start race strategy }\end{array}$ & $\begin{array}{l}\text { Ventilatory and energy expenditure } \\
\text { variables, race time, power output, } \\
\text { pace, StepMax, and race strategy }\end{array}$ & No & $\begin{array}{l}\text { Training with an avatar to use a fast-start } \\
\text { race strategy improved race strategy } \\
\text { profiles and race time performance at post- } \\
\text { test and retention test }\end{array}$ \\
\hline Ijsselsteijn et al. & 2004 & Experimental & $\begin{array}{l}\text { To determine if immersive VR } \\
\text { environments and a virtual coach } \\
\text { increase motivation to cycle }\end{array}$ & $\begin{array}{l}\text { (1) Immersion (high, } \\
\text { low) (2) Virtual coach } \\
\text { (with, without) }\end{array}$ & $\begin{array}{l}\text { Intrinsic motivation, HR, and average } \\
\text { speed }\end{array}$ & $\begin{array}{l}\text { The ITC Sense of } \\
\text { Presence } \\
\text { Inventory }\end{array}$ & $\begin{array}{l}\text { When VR was more immersive, motivation } \\
\text { and average speed were increased; the } \\
\text { virtual coach reduced perceived pressure, } \\
\text { tension and control }\end{array}$ \\
\hline Irwin et al. & 2012 & Experimental & $\begin{array}{l}\text { To determine if motivation to persist } \\
\text { would be influenced by the presence } \\
\text { of a partner in a conjunctive or } \\
\text { coactive situation }\end{array}$ & $\begin{array}{l}\text { (1) Individual (2) } \\
\text { Conjunctive (3) } \\
\text { Coactive }\end{array}$ & $\begin{array}{l}\text { Persistence, self-efficacy, intention to } \\
\text { exercise, ratings of perceived exertion, } \\
\text { and intention to exercise }\end{array}$ & No & $\begin{array}{l}\text { VR combined with a partner showed } \\
\text { greater task persistence in conjunctive } \\
\text { conditions than coactive conditions with } \\
\text { both higher than no partner }\end{array}$ \\
\hline
\end{tabular}



so the effect of imposed versus se selected VR tasks on affect and valence

(1) Bicycle ergometer with no VR (2)

Participant choice of VR

cycling or running (3)

Experimenter allocate

VR cycling or running

Mestre et al.

Experimental

To test the role of VR and a virtual coach on attentional focus, performance, and enjoyment

Murray et al.

Experimental

To determine if the presence of others in an immersive VR affects

performance, motivation, and affec during an aerobic rowing task

Nunes et al.

To determine if there is a difference in performance during a running task in the presence of a virtual competitor

To determine if self-selected o mposed exercise intensity and duration produce better cycling performance, affective responses, and enjoyment

\section{(1) No VR (2) VR (3) VR and following} virtual coach pacer

(1) No VR (2) individual VR (3) companion VR

(1) Single player only (2) Single player competitive against oneself (3) Competitive mode against a superior adversary (4) adversary (4) Competitive mode against an adversary
chosen by participant

\section{(1) Self-selected} intensity and duration with single virtual cyclist (2) Imposed intensity and duration with additional virtual cyclist

Plante et al.
A questionnaire designed to measure telepresence and social presence

No

Positive affect, negative affect,

Perceived exertion, physical activity enjoyment, attentional focus, and performance (speed, power, pedalling

Distance, power, strokes per minute, HR, exercise thoughts, perceived benefits and barriers to exercise, ratings of perceived exertion, affect, arousal, intrinsic motivation, and enjoyment of exercise

Performance (speed, heartbeat, and distance), perceived exertion,

HR, oxygen consumption, blood lactate, concentration, ratings of perceived exertion, affect, arousal, and enjoyment of exercise
Social presence rather than the VR technology itself was responsible for enjoyment, perceived value, and

behavioural intention

Mood benefits following the task were observed regardless of condition; a selfselected VR task resulted in higher positive valence during the task than when the VR type of task was externally imposed

Dissociative attentional focus was greater in the VR conditions and enjoyment was greater for VR condition than No VR condition and greater for VR with virtual coach than VR

Individual and companion VR resulted in better rowing performance and more enjoyment without an increase in perceived exertion; companion VR group exceeded ndividual VR group in distance travelled and HR

Participants reported the competitive mode was more motivating; perceived exertion and performance was higher in competitor conditions than in single player mode

No significant differences in performance or psychological outcomes across conditions were observed; there was a trend toward higher enjoyment in the mposed session

When cycling was paired with VR mood increased and tiredness decreased when compared to cycling alone 
To investigate whether VR enhance e psychological benefits of cyclin

Experimental

To test the effect of concurrent augmented feedback on learning and performance of a VR rowing task

Snyder et al.

Experimental

To examine the influence of a virtual versus live competitor on cycling intensity and energy exertion

Vogt et al.

2015

Experimental

To test the effect of exercise and VR immersion on cognitive performance
(1) Watch video

simulating a cycling

experience (2) Playing

VR computer bicycle

game without exercise

without VR (4)

Stationary cycling with

VR

(1) Visual feedback (2) Audiovisual feedback

(3) Visuohaptic

$$
\text { feedback }
$$

(1) Competitiveness level (2) Live or virtual competitor

(1) Session (active

cycling, passive

automatic drive) (2) VR

condition (front screen

only, surround with all

screens)
Mood, perceived exertion, social

\section{Cycling but not VR gave mood}

mprovements directly following the task; both VR and cycling decreased tiredness; VR showed psychological benefits hours after cycling for females only

Spatial error, temporal error, comfort, usefulness and applicability of feedback, and strategy for recalling taught movement

Competitiveness and cycling intensity (energy output, HR, and speed)

Cognitive performance, HR, sense of presence, and EEG amplitude and
Performance was better for all groups in feedback compared to no-feedback trials; audiovisual feedback produced better

learning and greater comfort than visuohaptic feedback

Participants who were highly competitive produced greater cycling intensity when competing against a live versus a virtual competitor

Sense of presence was associated with increased EEG activity; presence was highest in the surround VR condition during active cycling; cognitive performance did not differ across conditions

Note $: \mathrm{VR}=$ virtual reality; $\mathrm{HR}=$ heart rate; $\mathrm{BMI}=$ Body Mass Index. 